\title{
South African Higher Education: Emergent Issues and Debates
}

\section{Reitumetse Obakeng Mabokela}

Reitumetse Obakeng Mabokela recently received her Ph.D. educational policy studies at the University of Illinois, Urbana-Champaign. Address: 308 North Orchard Street, \#13, Urbana, IL 61801. Email: <mabokela@uiuc.edu>.

South African higher education has historically been $\checkmark$ characterized by racial and gender inequities inherited from the discriminatory policies of the apartheid era. As a result of the ascent to power of the Nationalist party between 1948 and 1983, universities and other institutions of higher education were divided along ethno-linguistic lines in accordance with the separatist policies of the former government.

The 1990s ushered in a new political era, characterized by the unbanning of political parties; the release of political prisoners - most notably Nelson Mandela, the current president of South Africa; and the shift of political power from the Nationalist party to the government of national unity led by the African National Congress. Since the change of government in 1994, there has been a concerted effort to transform the system of higher education from one marred by racial, gender, and class inequities, to one that is more equitable.

\section{Since the change of government in 1994, there has been a concerted effort to transform the system of higher educa- tion from one marred by racial, gender, and class inequities, to one that is more equitable.}

The need for transformation of the higher education sector is closely tied to the broader political changes that have taken place in South Africa since the change of government in 1994. The new government envisioned the creation of a nonracist, nonsexist society in all spheres of public policy, and education institutions are not exempt from these expectations. A number of issues have emerged as central to the debate surrounding the reconstruction of higher education. The three issues discussed in this essay-equality and access, the maintenance of academic standards, and the Africanization of academic institutions - have featured prominently in the discourse on higher education.

The first challenge in reconstructing higher education in South Africa is defining the term "transformation." Because this term is widely used by the various stakeholders involved in the process of change-students, faculty, administrators, and government officials - it has as many meanings as there are participants. These range from its characteriza- tion as a "Marxist-Leninist" process in which students eventually assume power to a less radical orientation dedicated to a shift in the basic mission of universities from serving the minority privileged community to serving the broader community. How can change be attained without a consensus among the major stakeholders regarding the nature and extent of that change? Other key debates in higher education are shrouded in the same degree of uncertainty.

\section{The first challenge in reconstructing higher education in South Africa is defin- ing the term "transformation."}

\section{Equality and Access}

Accommodating students from a broad cross section of social groups and classes is a key element in the transformation of the higher education system. This process of massification requires not only an increase and diversification of the student body, but other changes designed to accommodate the changing student population.

Currently, higher education access inequalities among blacks are partly attributable to their inadequate preparation at the primary and secondary education levels. The proportion of black students in a given age cohort who will complete high school currently stands at about 20 percent, compared to 80 percent of the students in a similar white cohort. ${ }^{1}$ This implies that the pool of black students who are eligible to enter university is significantly smaller than that of white students. Although the proportion of black students enrolled at universities increased at an annual average rate of 14 percent between 1986 and 1993 compared to an average annual growth rate of 0.4 percent for whites during the same period, this growth occurred primarily at historically black universities and at distance-learning universities.

The inability of black students to enter higher education has raised questions about the validity of matriculation results, which are still the legal criterion for admission at universities. While these results may be an accurate predictor of academic success among white students, this does not hold true for black students because of the inadequacy of secondary education for blacks. Given the unreliability of these results, some universities have explored alternative admissions criteria. The implementation of such criteria, however, has been largely dependent on internal linitiatives from individual universities. Some scholars question the philosophy underlying the current structure of alternative admissions programs, arguing that most programs operate from the assumption that black students are the problem and so that remedial teach- 
ing is the solution. This philosophy, they argue, assumes that there are pockets of underdevelopment in South Africa that can be dealt with while avoiding organizational change in the universities.

\section{Maintenance of Academic Standards}

Discussions about alternative admissions criteria have provoked fervent debates about the maintenance of academic standards. There is a pervasive perception that the increasing admission of black students at historically white universities will lower academic standards. The debate on standards identified three categories of respondents to this issue: first, those who argue that standards are declining as a result of the increased presence of historically excluded groups-blacks and women - into higher education. Second, those who contend that the standards debate is used by people who benefited in the past from discriminatory practices to impede access of blacks and women to higher education. And third, those who argue for the maintenance of positive elements from the past educational system, while attempting to raise standards in areas where performance was weak.

Current discussions about standards have failed to address questions of type and ownership. The current conception of standards assumes that quality and standards are bound to a single ahistorical and therefore universal model of a university, and that any departure from this model entails loss of quality. ${ }^{2}$ The primary focus is on bringing black students up to standard without much examination of institutional structures and the issue of redefining standards to meet the changing needs of the population they serve. W.M. Makgoba asserts that standards in South African institutions of higher education "were imported by the British to maintain British culture and values. They did not take into account the majority culture or civilization. They had no bearing on quality or relevance to their environment." ${ }^{3}$

Many historically white universities frequently cite their need to maintain high academic standards in order to compete at an international level. They operate with an implicit assumption that widening access to historically excluded groups will impede the ability of historically white universities to compete with their counterparts abroad.

\section{"Africanization" of Academic Institutions}

The debate over the maintenance of academic standards has stimulated another equally passionate debate about the "Africanization" of South African universities. The contentiousness of this issue emerges from a misunderstanding of what the concept means, and a false conception that Africanization is equivalent to a lowering of standards. Proponents of Africanization view it as, first, a way of changing the student, academic, and administrator bodies; second, a means of changing the syllabus so that teaching and learning are not dominated by "geriatric northern hemisphere cultures"; ${ }^{4}$ third, changing the curriculum and the whole way in which teaching and learning are done; and fourth, changing criteria that determine research excellence. As K. MacGregor explains, "someone who pleads for Africanizing our research programs is not pleading for lowering of standards, but simply asking that South Africans focus on problems that have their roots and significance in Africa." ${ }^{5}$ According to Makgoba, opponents of Africanization are primarily "conservative colonial descendants who fear that Africanization challenges their identity, culture, mindset, role, and privileges." He continues that Africanization challenges the superiority mentality of racism and the imitative philosophy that in the long term will lead to the perpetual enslavement of Africans. Further, he argues, Africanization challenges the "imposition of foreign and often alienating behavioral patterns and universities by outsiders that are not the primary interest of Africa."

\section{Current discussions about standards have failed to address questions of type and ownership.}

Present standards require serious scrutiny to determine which standards South African universities are evaluating themselves against, and the relevance of those standards given the sociopolitical conditions of the country. Otherwise, current standards have the potential to perpetuate discriminatory patterns of the past by defining blacks and women as the problem, without critically evaluating the structures of historically white universities.

This discussion of emergent issues is indicative of the challenges South African universities face as they attempt to forge a new identity as nonracist, nonsexist institutions. While this report does not cover all of the debate surrounding this process of change, it offers a glimpse at some of the critical issues with which South African universities have to contend.

\section{Notes}

1. I. Bunting, A Legacy of Inequality: Higher Education in South Africa (Rondebosch: UCT Press, 1994), 40.

2. H. Wolpe, "Introduction: Context, Principles and Issues in Policy Formation for pse," in Draft Policy Proposals for the Reconstruction and Transformation of Post Secondary Education in South Africa (Bellville, South Africa: Education Policy Unit, University of Western Cape, 1994).

3. W. M. Makgoba, "Academic Standards: Myth or Reality?" New Nation, May 31, 1996, vii.

4. K. MacGregor, "Getting to Grips with Africanization," New Nation, May 17, 1996, vii.

5. Ibid.

6. Makgoba. 